\title{
REFERENCES
}

Guttmann Ludwig (I94I). Proc. Roy. Soc., 35, 305-308.

- (1945). New hope for spinal cord sufferers. N.Y. med. Times, 73, 318.

(1953). The treatment and rehabilitation of patients with injuries of the spinal cord. Monograph in Vol. Surgery, Medical History of the Second World War, pp. 422-5I6. London: H.M. Stationery Office. (See previous references on management and research.) (1954). Visceral activity and peripheral circulation in the spinal man. Ciba Foundation Symposium on Peripheral Circulation, pp. 192-203. (See previous references on research.) London: Churchill.

- (1962). Sport and the disabled (see previous references on sport). Sports Medicine, pp. 367-39i. London: Arnold. (1962). Our paralysed fellowmen at work. Rehabilitation, 43, 9-I 7.

- (1965). Services for the treatment and rehabilitation of spinal Paraplegics and tetraplegics in Great Britain. Trends in Social Welfare, pp. 319-336. Pergamon Press.

\section{THE SPINAL CORD INJURY CENTER OF THE VETERANS ADMINISTRATION HOSPITAL, LONG BEACH, CALIFORNIA, U.S.A.}

\section{Facts and Thoughts}

By ERNEST Bors, M.D.

\begin{abstract}
From The Spinal Cord Injury Service of the Veterans Administration Hospital, Long Beach, California, and the Department of Surgery of the University of California at Los Angeles, Los Angeles, Calif. 90024
\end{abstract}

SiR Ludwig GutTMANN invited me to prepare this report. It should be stressed that the views and opinions expressed in this paper are my own and do not reflect those of the Veterans Administration of the United States. However, I should like to state that the Veterans Administration has had great foresight and vision in permitting the development of its eight centres according to the needs and potentials of the areas in which they are located. Thus, units were created based on a loose table of organisation rather than on strict uniformity.

Because of this freedom, our unit at Long Beach has enjoyed a great deal of autonomy, although occasionally the clash of the two philosophies can be felt which today encompasses medical education in general, namely the struggle of treating disease by entity rather than by department. The development of modern medicine makes teamwork necessary and functions of departments may overlap. To quote an example: renal transplantations require a team of internists, immunologists and surgeons. In some places the surgical sub-team consists of a vascular and urological surgeons, in others the urologists do all the necessary surgery. Thus, borderlines between departments or divisions are slowly vanishing and a more catholic approach is resurging, reminiscent of the times 50 years ago when sub-specialties were just emerging. This approach applies, in my opinion, also to the management of a spinal cord injury unit. 
The physical plant and organisation of our unit in Long Beach has been described by A. Rossier (1963); since the time of his report, some extensions and alterations have occurred. A special laboratory has been activated for physiological and neurophysiological studies in spinal man; this is not located on the premises of the unit proper but in the research building which houses many laboratories. Furthermore, two rooms of the unit have been converted into renal laboratories for radioisotope renal scintiscan and renogram procedures. The Government and, in part, donations from philanthropic societies have made this progress possible. Another addition to the original unit (Rossier, 1963) will be the enlargement of the present out-patient clinic into a compact building attached to the unit. It will have waiting, examining and supply rooms, as well as offices for the physian, nurse and secretary. We hope that this new clinic will open in the late months of I968. Such an addition has become necessary by the everincreasing number of out-patients; it will not affect the bed capacity of 205 for in-patients.

Historically, the development of the present unit can be traced to its humble beginnings in the Army in 1944 and 1945. Patients with spinal cord injury during World War II were then housed in a large neurosurgical section of the Hammond General Hospital at Modesto in Central California, where I served as a member of the urology staff. Since urology undoubtedly is one discipline which deals with the most common complications of these patients, it was decided to transfer these patients from the neurosurgical to the urological wards in order to facilitate their care. Approximately 70 patients belonged to that unit. At the end of 1945 , all patients from our own and three other hospitals with neurosurgical units, within the 9th Service Command, were transferred to the Birmingham General Hospital in Van Nuys, California, close to Los Angeles. That Army Spinal Cord Injury Center started with I80 patients, but their numbers swelled quickly to approximately 220 after the Veterans Administration had taken over from the Army in the spring of I946. The Veterans Administration was very generous in supporting the project of a Spinal Cord Injury Center and created not only the foundation for the present facilities but also that policy which made the unit quite autonomous. In June of 1950 the entire complex of Birmingham General Hospital, patients, personnel and a great deal of equipment and supplies, were transferred to what until then was the Navy Hospital in Long Beach, California, about 30 miles southeast of Los Angeles. The unit remained housed in so-called semi-permanent barracks; enlargement of some facilities resulted from that move, so that a cystoscopy room with two tables, instead of one, central bath and toilet rooms, and an operating room for minor surgery, were available for the first time. In September of 1958 the newly built permanent quarters were occupied by our unit, as described by Rossier (1963). They are located on the first floor of five wings, attached to the permanent structure of the original Navy Hospital. Each of these wings has three floors and a basement. The latter contains the facilities of the Physical Medicine and Rehabilitation Service, which includes among others, a separate gymnasium and Physical Therapy Clinic for spinal injury patients.

Since its activation under the Veterans Administration, 2232 patients have passed through the unit as of 3I May 1967. Of that total, 2073 had traumatic and I59 non-traumatic cord lesions. The latter include vascular accidents, primary or metastatic tumours of the cord, sequelae of surgical interventions, 
e.g. discogenic diseases, and neurologic deficits resulting from transverse myelitis. Poliomyelitis, myelodysplasia and demyelinating diseases of the cord, e.g. multiple sclerosis are not treated as a rule on the Spinal Cord Injury Service which, as the name indicates, is chiefly concerned with spinal cord trauma.

It seems logical that anyone, irrespective of his specialty, who wishes to serve these patients afflicted with a neurological disorder should familiarise himself with the basic principles of neuroanatomy, neurophysiology and neurologic examination: excepted are neurologists or neurological surgeons who had formal training in these fields. It also goes without saying that such a man will have to forgo some of the work connected with his original specialty, whether this was surgery, medicine, or their respective sub-specialties, physical medicine, psychiatry, neurological surgery or neurology, because that physician will have to devote his attention to all aspects of a patient whose requirements are multi-disciplinary. My past formal training in anatomy, surgery and urology has been valuable; it expedited the learning of basic neurology, the performing of operative procedures, other than urological, the understanding of what modalities in physical medicine, corrective or occupational therapy might benefit the respective patient's rehabilitation; but it helped especially when consultations from other surgical specialties had to be considered and integrated into the scheme of all therapeutic procedures. This role to co-ordinate the activities of surgical sub-specialties is easier for those who were trained at a time before sub-specialisation reached its present peak. I learned a great deal from all consultants, especially from my orthopaedic, neurosurgical and neurological colleagues; but also the psychologist, psychiatrist and social service worker widened the scope of my knowledge regarding the patient's social and economical rehabilitation which is the ultimate goal.

As a urologist I had to learn to drop some orthodox approaches which may be good for patients with an intact neuraxis but not for one with a neurological disorder. Most of all I had to learn patience, to listen to, rather than to force Nature, to adjust rather than to attack, to observe, deduce and not to try to play Providence. Anxious as all of us are to improve old methods and to develop new ones in an attempt to prevent renal deterioration, it seems strange that the more aggressive approach should come from quarters less experienced in the management of large number of patients than from medical personnel serving in units. It is my credo that a urologist, not thoroughly familiar with neurological examinations and with the wealth of the literature in the field of genito-urinary sequelae of neurological disorders, should acquire this necessary knowledge before he advocates hasty and ill-indicated interventions. My credo is based upon the results of quite a number of patients operated on elsewhere whose case histories would by far exceed the space and scope of this report.

Surgeons are extroverts and as such are usually not endowed with too much insight, they are honestly unaware of some of their motivations which indicate surgery. Without wishing to enumerate the host of motivations in detail, just one should be mentioned; some surgeons are so much in love with the skill of their hands during surgery that the fingers 'run away' with the brain, because the latter supplied emotions unbridled by judgment. Anyone in my specialty of urology should live for years among our patients before starting to collect a 'series' of so-called preventative operations; poor results remain either unknown for lack of followed-up or are, perhaps, repressed and conveniently forgotten. 
Our unit occupies a part of a I600-bed medical and surgical general hospital, which includes services of psychiatry, psychology, physical medicine and rehabilitation, chest diseases, and large Research Unit. There can be no doubt that a spinal injury centre benefits from its location in a general hospital, for several reasons: expert consultants, teaching and investigative activities make working in academically satisfactory surroundings attractive for those physicians and surgeons serving in a spinal injury unit; if a spinal injury centre were entirely isolated, and not affiliated with a general hospital, recruitment of medical personnel would meet with difficulties.

From its activation under the Veterans Administration in 1946 our hospital has been, and still is, a teaching hospital, operating under the auspices of a Dean's Committee, in order to provide formal training according to the requirements of the respective Specialty Boards. It has been from the beginning, and still is, affiliated with three universities located in Southern California. This provides a stimulating atmosphere, conducive to good patients' care, furthered by teaching and particularly basic research, so important for a spinal unit.

All of these above-mentioned factors have been instrumental in procuring and keeping a high-quality medical staff for our unit. Of the ro physicians and surgeons on our service, three are Board certified in urology, one in physical medicine and rehabilitation, one in surgery, one in psychiatry and neurology; and three are eligible for Board examinations in surgery or medicine, respectively. This means that 9 out of Io had formal training in a specialty.

The quality of the medical staff on the unit has permitted its subdivision into five sections: Neurological Urology Section (independent of the general urology section of the surgical service), Outpatient Section, Medicine and Laboratory Section, Physical Medicine and Rehabilitation Section, and the Ward Section; the latter consists of five wards with 4I beds each. Thirty-two beds are in a large ward, arranged in eight cubicles, each with four beds, and nine beds are in five rooms; of these, four are equipped with two beds and one has one bed. Further details can be found in Rossier's (1963) report as regards other facilities, such as bathrooms, toilets, minor surgical operating room, cystoscopy clinic, etc. As mentioned above, a new addition was the conversion of two rooms for radioisotope renal scintiscan and renogram procedures. The work produced there is a joint project of the Spinal Cord Injury and Radioisotope Services of the hospital, but the Chief of the Medicine and Laboratory Section is primarily responsible for the function and productivity of the renal laboratory.

Each of the five wards has one physician in charge, which leaves four Section Chiefs and one Service Chief, to make a total of ro medical personnel. By directing the section of Neurological Urology and the Ward Section, the Assistant Chief of the Service, Dr. A. E. Comarr, has de facto a triple responsibility. He played an integral part in building the Service to its present quality during the past 2I years, first as my pupil and thereafter as my loyal associate and dear friend. We were indeed fortunate to have had other staff members with us who have served on our unit anywhere from I4 to almost 20 years. Since stability and continuity of medical personnel is of distinct advantage for managing the Service, it has been our policy to assign only physicians who are willing to stay a minimum of one year.

While it is stimulating to have residents of various specialties, urology, 
physical medicine and rehabilitation, neurosurgery, and neurology, affiliated with the Service, past experience in other spinal injury centres has shown that the exclusive management of a unit by residents is ill-advised, because of their shortterm assignment due to frequent rotation; also their interests are too closely focused on their own respective specialty rather than on the patient as an entity.

What was just said about the stability of the medical staff applies also to the nursing and paramedical staff. i.e. personnel in physical, corrective and occupational therapy. It is our good fortune to have a Nurse Supervisor who served on our unit since 1947, with an interruption of about seven years. Some nurses have been assigned for over 17 years who are now in charge of wards; some corrective therapists have been with us for eight or more years. As long as a cadre of medical, nursing and paramedical personnel can be maintained, the in-service-training can be easily kept up.

As far as the personnel-patient ratio is concerned, the following total figures are desirable: I physician to 20 patients; 0.93 nursing personnel to I patient; this is by 0.07 less than originally advocated in the Technical Bulletin in 1948; included are registered nurses, licensed vocational nurses, and nursing assistants; 7 paramedical personnel to Ioo patients, i.e. 3 physical therapists, 3 corrective therapists and I occupational therapist. In addition, there should be available and attached to the unit I psychologist and 3 social service workers. This goal is not always attainable, but one should aim at it, because experience has shown that a decline of numbers reflects on the quality of patients' care, an intangible value which cannot be measured, in spite of many modern administrative attempts to standardise and computerise input versus output as if man were a factory product.

Teaching is an integral part of the unit's activity. Weekly and monthly conferences, and weekly rounds and clinics are a necessity in order to maintain not only patients' care but also the interest and education of the entire personnel. Special weekly courses are given as in-service training, designed primarily for nursing personnel but open to anyone interested in the respective subject. Mutatis mutandis, all personnel are invited to attend Medical Conferences as their time permits.

In closing, it is only fair to state that the activities, organisation and physical layout have been found appropriate for our unit. Each of the eight units of the Veterans Administration has been given an individual leeway, to develop in accordance with its respective requirements and with the labour markets which vary greatly in different geographical locations. What applies to Southern California on the West Coast may not be right in the Middle West, South, or on the East Coast of the United States. However, in spite of such geographical differences, the basic medical management is essentially much alike in all units.

\section{REFERENCES}

Bors, E. (1948). Spinal cord injuries. Veterans Administration Technical Bulletin, I0, 503, December I5.

Rossier, A. (I963). The organization and function of the Spinal Cord Injury Service of the Veterans Administration Hospital, Long Beach, California. F. int. Coll. Surg. 39, 225-237. 